\title{
Violence and Diversity: Teachers in Training's Perspective
}

\author{
David Caballero Mariscal, Prof. Dr.
}

\author{
University of Granada \\ Email: davidcaballero@ugr.es
}

Guadalupe Alba Corredor, Prof. Dr.

University of Granada

Email: guadalupe@ugr.es

\section{Doi:10.5901/mjss.2015.v6n2s1p34}

\begin{abstract}
The main focus of this study is to underline the relevance of improving teachers in trainer's education as far as inclusion of minorities, cultural diversity and gender prejudices is concerned. In order to measure these aspects, we administered the Questionnaire on attitudes towards diversity and violence. This instrument, created by Díaz-Aguado, Martínez and Marín (2004) evaluate different sorts of believes that could lead to exclusion and aggression. The Questionnaire consists on 71 items, divided in three dimensions. In any case, for this research we only used the first one, which is divided into four factors. The participants $(N=364)$ were students of the Faculty of Education. We tried to know the different attitudes between men and women of different ages at this respect. For this proposal, we carried out different analysis: means, standard deviation, and ANOVA's. The result show significant differences in gender, age and gender $x$ age in Factor 1 (justification of peer violence as a reaction, and courage); besides in gender in Factor 2 (sexist beliefs and justification of gender violence) and, in turn, in age in Factor 3 and 4 (Intolerance and justification of violence towards minorities and as punishment and Agreement with tolerant believes and rejection of violence).
\end{abstract}

Keywords: future teachers, attitudes, violence, cultural diversity

\section{Introduction}

Teacher's influence is essential in order to build a better society. Current society is characterized by several factors we cannot forget, among them, multiculturalism and social diversity, and new challenges as well. It is obvious that diversity contributes to social enrichment. On the other hand, it is necessary to underline this growing situation carries implications for today's society. In this sense, values education becomes a priority. That is why teachers exert an important influence in the development of values in children, in special, peace, solidarity, equality and diversity. If teachers are not educated in this direction, they will not be able to transmit these important values. Due to these circumstances, they must be adequately-trained to provide education and to build a more tolerant world. In this regard, the task of preparing teachers is a responsibility that begins in programs at education faculties or institutes of higher education. As far as this is concerned, many authors underline the importance and responsibility of educational institutions in the development of preparing in sensitivity and positive attitudes towards social and cultural diversity (Weddington and Rhine, 2006). Teachers exert an important influence of on children in the acquisition of values.

We must emphasize that the university, and more specifically, those studies directly linked to society and education, has a privileged role in developing social skills and values. On the other hand, these university centers are also places where future professionals, in this specific case, teachers, must amplify their perception and consciousness of cultural and social diversity. We cannot deny that society has experienced a deep process of change in a short period of time and over recent decades multiculturalism has become de prior reality in contemporary contexts. That is why many situations or aspects, those were not important few years ago, have turned to be the most important to take into account in order to grow, or even to solve social problems. In this sense, any teaching-student aspires to be good professional teachers and they are conscious or their responsibility, due to the influence in their students' lives they can have. On the one hand, teachers tend to become positive models for the children and they usually repeat values and behavioral patterns. In an indirect way, children emphasize those values or rules they learnt at home, or at least, they unconsciously contrast both models. We cannot forget there are growing difficulties in our societies and they often have an important 
effect on families, due to endogenous and exogenous factors. On the other hand, teachers in training have a double and privileged perspective: they are students and semiprofessionals as well. That is why they try to avoid the errors they can remember when they were children. And in turn, during their training period at schools, they can develop new attitudes after they have observed different perspectives. Still, new teachers, including those in training, tent to embrace the behavioral models they know due to several reasons, among them, the perception they have about the right models. That is why the way they normally educate is similar to the way they were educated, often following obsolete models, because they grew up in very different context which has nothing to do with today's society (Oleson and Tadashi Hora, 2012). Still, if teachers are not trained in values, it could be difficult to fulfill the latter proposition. We must underscore many researchers underline that new teachers are inclined to repeat the patterns they acquired (Handler, 1993). Teachers have a propensity to discharge their responsibility, influenced by their educators. To teach in the way they learn can suppose to repeat similar mistakes.

On the other hand, our society has undergone deep transformations and significant changes in values, social relations, customs and structures.

New society is characterized by cultural and ethnic diversity. These new challenges must be faced by professionals who can understand new situations and the multiculturalism, a reality which offers a chance to construct a society opened to multiculturalism and diversity. In this context, educators have the responsibility of "transmitting and implanting social values, such as democracy, equality, tolerance, cultural understanding, and respect" (Macbeath, 2012, p. 3).

Values education is a priority and this fact implies multicultural education, and education for peace, solidarity and gender equality. Still, in order to get this goal, it is completely necessary to develop all these attitudes in future professionals. To enhance teachers in trainers' consciousness and positive attitudes towards diversity, it is necessary to get proficient in several fields, in such a way that they can later transmit all these attitudes and values to their students at schools.

To build a fair society, characterized by tolerance, justice and equity, there are many factors we cannot forget. Family is the main factor in the acquisition of attitudes and social skills. On the other hand, children teach how to understand world and society by means of the family, and in turn, the school and the media. On the other hand, children spend many hours a day at schools. That is why teachers bear an influence on their student, and by extension, on society. If they have positive values and good attitudes towards multiculturalism, social diversity and gender equality, they will be able to transmit all these attitudes in a coherent and consistent way (Deardorff, 2012). Due to the different expressions of prejudices and intolerance, those are very manifest in current society, it is very important to combat this lack of minimum values. Teachers usually have an important authority in their students, not just in knowledge, but social skills and personal attitudes as well. That it is why it seems to be completely necessary to underscore the significance of teachers' training:

The task of initial teacher education is to prepare people to enter a profession which accepts individual and collective responsibility for improving the learning and participation of all children" (Florian and Rouse (2009, p. 596).

Singh (2011) underscores "inculcation of values among the students can play a very important role by shielding them from negative influences" (p. 1), and this situation is mainly due in part to "consumerism and an aggressive rush for self fulfillment" (p. 1). At this respect, Reynolds considers teachers are an important and unavoidable reference in the development of positive attitudes of tolerance and, in turn, towards diverse social and cultural groups, in other words, intercultural education. In this regard, values education is directly related to professional effectiveness in teaching, as far as quality is concerned (Lovat and Toomey, 2009). If educators teach how to value cultural and social differences, children will be able to appreciate this diversity as richness, in the context of a changing world.

We must affirm the relevance of teachers in the transmission of values and social skills. On this basis, a significant part of all those values acquired from childhood, persist in young people and, moreover, in adult life (Viniegra, 2007). It would be a priority to include accurate programmes which can contribute to the development of these values and constructive attitudes towards differences. In this sense, all the previous teacher's (and future teacher's as well) values and perspectives play a pivotal role in children. As we have previously underscored, teachers will be a reference and a model in crucial aspects.

We must take into account we are in a changing society. Europe is currently characterized by diversity, because of the immigrant flow. That is why we can justify this research, in the context of a partial rereading of traditional values and beliefs. Due to this, the focus of this paper is to research and reflect about attitudes towards diversity, gender violence and minorities of teachers in training. 


\section{Research Methodology}

\subsection{Participants}

The study population consisted of 364 university students (teachers in training); 125 males (34.34\%) and 239 females $(65.66 \%)$, ranging in age from 18 to 44 . These students presented a mean age of 21.02 (ST=3.22). The $90 \%$ of the sample was younger than 24. To a deepest description of the age distribution, see Table I.

Table I. Age distribution of participants

\begin{tabular}{ccccccccccccccccccc}
\hline Age & $\mathbf{1 8}$ & $\mathbf{1 9}$ & $\mathbf{2 0}$ & $\mathbf{2 1}$ & $\mathbf{2 2}$ & $\mathbf{2 3}$ & $\mathbf{2 4}$ & $\mathbf{2 5}$ & $\mathbf{2 6}$ & $\mathbf{2 7}$ & $\mathbf{2 8}$ & $\mathbf{2 9}$ & $\mathbf{3 0}$ & $\mathbf{3 1}$ & $\mathbf{3 2}$ & $\mathbf{3 3}$ & $\mathbf{3 4}$ & $\mathbf{4 4}$ \\
\hline $\mathbf{N}$ & 58 & 88 & 67 & 41 & 21 & 29 & 21 & 12 & 5 & 2 & 7 & 3 & 3 & 1 & 2 & 2 & 1 & 1 \\
\hline
\end{tabular}

\subsection{Variables and Instrument}

Cuestionario de Actitudes hacia la Diversidad y la Violencia [Questionnaire on attitudes towards diversity and violence] (CADV) created by Díaz-Aguado, Martínez and Martín (2004). This instrument asses the sort of beliefs that could lead to exclusion and aggression. It includes three dimensions, evaluated over 71 questions. Still, for this study was used only the first one, which has four subscales or factors.

The variables included in the four subscales are: 1) justification of peer violence as a reaction, and courage (16 items); associating peer violence with displays of courage; 2 ) sexist beliefs and justification of domestic violence (17 items); justifying the man as head of the family, sexist discrimination, child abuse and violence towards women; 3 ) intolerance and justification of violence against minorities and as a punishment (14 items); xenophobia, racism, rejection of tolerance and diversity, justification of violence against minorities who are perceived as different; and 4) agreement with tolerant beliefs and rejection of violence (7 items).

The answers are based on a 7-point Likert scale in which 1 means strongly disagree and 7 strongly agree. The scale structure was confirmed using reliability analysis with best fit values for the variables. The analysis produced the following internal consistency indices: factor $1 a=.85$, factor $2 \alpha=.85$, factor $3 a=.82$, and factor $4 a=.67$

\subsection{Design}

The research methodology was an ex post facto one-group design, due to the researcher has no direct control over the independent variables, because the manifestation happened or intrinsically no-manipulated (Bernardo y Caldero, 2000).

\subsection{Procedure}

First of all, the researchers reported to the Dean of the Faculty (Education Faculty) about the research and asked for the needed permissions. After getting the consent from the Center, the main researcher had a meeting with the professors involved in the study, in order to request permissions to collect the data. Furthermore, the same professor undertook the responsibility of obtaining the consent of students.

The collected data were carried out in the first semester of the academic year 2014. The instruments were filled in the last 10 minutes of each class by each student. Neither the name nor the identity was required in this sense, so the questionnaire was totally anonymous and voluntary.

\subsection{Data Analyses}

Firstly, a series of descriptive analysis as means and standard deviations were run.

In a second moment, several analyses of variance (ANOVA) on the variables sex (2) $x$ age (8) were run in order to examine the differences between participants. Some post hoc analyses were performed to find out the variables in which the interaction effects were significant.

Statistical Package for the Social Sciences (SPSS) in the Statistics 22 version for Windows was used for the different analyses. 


\section{Results}

The means and standard deviations of responses by variable are shown in Table II.

Table II. Descriptive statistics, means and standard deviation of responses by sex and age

\begin{tabular}{|c|c|c|c|c|c|c|c|c|}
\hline & \multicolumn{2}{|c|}{ Factor 1} & \multicolumn{2}{|c|}{ Factor 2} & \multicolumn{2}{|c|}{ Factor 3} & \multicolumn{2}{|c|}{ Factor 4} \\
\hline & $M$ & SD & $M$ & SD & $\mathbf{M}$ & SD & $M$ & SD \\
\hline \multicolumn{9}{|l|}{ Sex } \\
\hline Male & 2.22 & 0.76 & 1.88 & 0.55 & 2.96 & 1.15 & 4.98 & 1.13 \\
\hline Female & 1.65 & 0.55 & 1.57 & 0.55 & 2.88 & 1.12 & 4.84 & 0.96 \\
\hline \multicolumn{9}{|l|}{ Age } \\
\hline 18 & 2.11 & 0.77 & 1.87 & 0.69 & 3.22 & 1.12 & 4.45 & 1.00 \\
\hline 19 & 1.91 & 0.77 & 1.64 & 0.50 & 2.73 & 1.09 & 4.90 & 1.00 \\
\hline 20 & 1.85 & 0.62 & 1.71 & 0.51 & 3.09 & 1.28 & 4.77 & 1.00 \\
\hline 21 & 1.74 & 0.71 & 1.73 & 0.55 & 2.97 & 0.95 & 4.90 & 1.07 \\
\hline 22 & 2.20 & 0.95 & 1.86 & 0.67 & 3.09 & 0.91 & 5.22 & 0.95 \\
\hline 23 & 1.71 & 0.58 & 1.80 & 0.77 & 2.79 & 1.23 & 5.20 & 1.10 \\
\hline 24 & 1.91 & 0.55 & 1.58 & 0.46 & 2.57 & 1.15 & 5.39 & 1.07 \\
\hline 25 & 1.51 & 0.35 & 1.39 & 0.33 & 2.16 & 0.45 & 5.82 & 0.55 \\
\hline 26 & 2.00 & 0.54 & 1.54 & 0.30 & 3.24 & 1.04 & 5.46 & 0.69 \\
\hline 27 & 2.31 & 1.33 & 2.06 & 0.75 & 4.75 & 1.67 & 4.21 & 0.91 \\
\hline 28 & 1.88 & 0.69 & 1.44 & 0.32 & 1.91 & 0.79 & 6.00 & 0.65 \\
\hline 29 & 2.06 & 0.22 & 1.69 & 0.33 & 2.45 & 0.53 & 5.43 & 1.51 \\
\hline 30 & 2.25 & - & 1.94 & - & 4.14 & - & 5.14 & - \\
\hline 31 & 2.06 & - & 1.18 & - & 2.79 & - & 4.86 & - \\
\hline 32 & 1.00 & 0.00 & 1.00 & 0.00 & 1.64 & 0.91 & 5.29 & 1.21 \\
\hline 33 & 1.38 & - & 2.18 & - & 2.14 & - & 5.43 & - \\
\hline 34 & 1.38 & - & 1.09 & - & 2.07 & - & 5.71 & - \\
\hline 44 & 1.19 & - & 1.12 & - & 1.86 & - & 6.14 & - \\
\hline
\end{tabular}

The ANOVA results for Factor 1, justification of peer violence as a reaction and courage, show significant main effect for $\operatorname{sex} F(1,363)=13.36, p<.001, \eta^{2}=.08$, and age, $F(17,347)=2.39, p=.002, \eta^{2}=.11$. Scores were significantly higher among males than females, and among younger student than older. The interaction factor sex $x$ age was significant, $F$ $(11,353)=2, p=.027, \eta^{2}=.06$, The variable sex is responsable for the variance in Factor 1 to a moderate degree $(8 \%)$ as well as age (11\%).

Respect to Factor 2, sexist beliefs and justification of gender violence, results show a significant main effect only for sex, $F(1,363)=6.64, p<.001, \eta^{2}=.04$. Males seem to score higher in sexist beliefs and their justification than women. Both, age and the interaction factor were not significant. The variable sex is responsible for the variance in Factor 2 to a low degree (4\%).

For Factors 3 and 4, intolerance and justification of violence against minorities and as a punishment and agreement with tolerant beliefs and rejection of violence, respectively, the results show significant differences in age $F$ $(17,347)=2.12, p=.006, \eta^{2}=.1$ and $F(17,347)=1.78, p=.029, \eta^{2}=.08$, respectively. The variable age is responsible for the variance in Factor 3 to a moderate degree (8\%) as well as Factor $4(10 \%)$.

\section{Discussion}

This research was focused on the evaluation of teachers in training's attitudes towards different cultural and social minorities and gender violence (both females and males). This goal was analyzed taking into account both these main hypotheses: (1) sex affects an individual's understanding of diversity, minorities and gender violence, (2) age does not affect an individual's understanding of diversity, minorities and gender violence. The final results partially endorse both hypotheses.

As far as the first item is concerned (justification of the peer violence as a reaction and courage) it is completely necessary to accentuate there are significant differences between both sexes. In this sense, males obtained higher scores in this variable, sustaining this certainty. We cannot forget, different researchers underscore men often are inclined to justify the use of violence in a greater or lesser extent. 
On the other hand, we could also find important divergences, reflected in the high scores obtained in sexist beliefs by males. Furthermore, there is an obvious justification in younger student as far as the peer violence as a reaction is concerned. This attitude tends to be more significant at this interval of age.

Furthermore in factor 2, males scored higher in the second factor (sexist beliefs and their justification in gender violence) than females.

On the other hand, if we consider those items which refer to intolerance, justification of violence against minorities and as punishment; and agreement tolerant beliefs and rejection to violence, respectively, final results revealed important differences in age. We must underline similarities in reference to gender and attitudes towards diversity if we take into account other studies. Thereby, some authors as Alonso, Navarro and Vicente (2007) underline the relevance of deploying programs in order to increase values and attitudes of tolerance towards diversity, even considering the positive outcomes they could find in their respective studies. Still, these authors give emphasis to the lack of significant differences between genders.

If we take into account the final results, we should call attention to the different deep-rooted cultural and social prejudices, leastwise in extent of some groups. That is why social abilities and intercultural competence should be a priority in early education in order to increase the development of these capabilities. Some researches show the relation between primary intervention and the later social adjustment in adulthood. These aspects should be directly included in the school curriculum. All these difficulties and obstacles we have underlined above will decrease gradually if schools promote values and attitudes (Díaz-Aguado, 2005). In education, and more specifically, in those university students who would like to become educators, including teachers in training, the acquisition of certain attitudes and values becomes imperative. On the other hand, equality education it is also a priority to prevent violent attitudes, which can persist along the time, if preventive measures are not taken, since these behaviors and attitudes tend to persist along the time in teenagers and young people in general if they are not increased awareness about these matters (Alberdi and Rojas, 2005. Due to this, violence cannot be considered as an alternative or response by any means. In turn, it cannot be justified. Many different programs have been developed over the past three decades to increase gender equality and positive attitudes towards diversity. They demonstrate wrong myths and false stereotypes and distorted prejudices can be changed. This is likely an effective way of avoiding ethnocentric attitudes and gender violence (Carrión-María, LópezEspín, Gascón-Cánovas and Torres-Cantero, 2012).

Values education and training social abilities constitute an essential part of education to develop positive attitudes towards diversity and gender equality. There are differences in human beings as far as traditions, beliefs, ways of life and cosmovisions are concerned. Still, these differences can contribute, in turn, to social enrichment (Fermín, 2007). That is why we all must put forth adequate effort to build an inclusive society, characterized by values and tolerance (Pérez, 2004).

Multiculturalism and intercultural societies are promoting important changes and challenges as well, in education. Our society is changing quickly and diversity is increasing. As a result of these circumstances, and following Tarman and Tarman (2011) "educators today suggest infusing multicultural content into the entire curriculum" (p. 578). If one of the schools and teachers' priorities is to increase either social values or positive attitudes towards different and diverse groups, we cannot only accentuate the importance of knowledge and culture, but the transmission of values. Gorski (2008) underscores "teachers who believe and put into practice "multicultural education's chief concern is interpersonal harmony". On the other hand, "the goal of this approach is to "improve feelings and communication in the classroom and in the school as a whole through interpersonal relations and prejudice reduction (Gorski, p. 310). Teachers are decisive as role models, and in turn, in values education. Due to current demands, it seems to be completely necessary to develop effective programs to contribute to social and cultural diversity, including education for gender equality. This is a priority that official curriculum should not forget by any means (Montero, 2000). To get these goals require an important training in teachers, but it is necessary to take into account more aspects. Still, to get a meaningful multicultural education to occur, personal transformation is necessary (Hoshmand, 2004).

If we take into account the results obtained, and as we previously underlined, future teachers in training should be direct effort into developing these values, to appreciate, respect or value this important social and cultural diversity. This is likely the right way to develop skills and, in turn, to become optimal teachers. This is a real exigency for educators. They can deeply contribute to improve society in this context of changing world. Social values can be considered as priority in this multicultural stage. Chou (2007) underlines that, due to these new challenges, "Instruction of teacher education are examined to uncover the prevailing trend", as far as diversity is concerned. Teachers bear an important influence on their students. That is why they should take into account their values and reflect on them to develop a positive attitude to new cultures and, in turn, to equality gender. On the other hand we cannot forget education and diversity carry implications. Llera, Saleem, Roffman and Dass-Brailsford (2009) consider "this education involves an 
understanding of the relationship between social justice and identity development within a socio-political context" (p. 59). If we understand relation among ethnics, social groups and gender in different context, we will be able to develop accurate tools to transmit values.

\section{References}

Alberdi, I., \& Rojas, L. (2005). Violencia: tolerancia cero. Barcelona: Fundación "La Caixa".

Alonso, M. J., Navarro, R., \& Vicente, L. (2007). Actitudes hacia la diversidad en estudiantes universitarios. Tretzenes jornades de foment de la investigació. 13, 1-16.

Bernardo, J., \& Caldero, J.F. (2000). Investigación cuantitativa (4); Métodos no experimentales. En J. Bernardo, y J.F. Caldero, Aprendo a investigar en educación (pp. 77- 93). Madrid: RIALP, S.A.

Carrión-María, M. C., López-Espín, J. C., Gascón-Cánovas, J.J., \& Torres-Cantero A. M. (2012). Validez y fiabilidad de un cuestionario abreviado para medir actitud autoritaria en adolescentes. Anales de psicologia, 28, 188-195.

Chou, H. M. (2007). Multicultural Teacher Education: Toward a Culturally Responsible Pedagogy. Essays in Education, 21, 139-162.

Deardorff, D.K. (Ed.). (2009). SAGE Handbook of Intercultural Competence. London: Sage.

Deardorff, D.K. (2012). Intercultural Competence in the 21st Century: Perspectives, Issues, Application. In Breninger's Creating Cultural Synergies (Cambridge Scholars). Invited chapter.

Díaz-Aguado, M. J., Martínez Arias, R., \& Martín Seoane, G. (2004) Prevención de la violencia y lucha contra la exclusión desde la adolescencia. La violencia entre iguales en la escuela y en el ocio. Madrid: Injuve.

Díaz-Aguado, M. J. (2005). La violencia entre iguales en la adolescencia y su prevención desde la escuela. Psicothema, 17 (4), 549558.

Fermín, M. (2007). Retos en la formación del docente de Educación Inicial: La atención a la diversidad. Revista de Investigación, 62, 71 91.

Florian, L.. \& Rouse, M. (2009). The inclusive practice project in Scotland: Teacher education for inclusive education. Teaching and Teacher Education, 25 (4), 594-601.

Gorski, P. C. (2008). What we're teaching teachers: An analysis of multicultural teacher education coursework syllabi. Teaching and Teacher Education, 25, 309-318.

Handler, M. G. (1993). Preparing new teachers to use computer technology: Perceptions and suggestions for teacher educators. Computersin Education, 20 (2), 147-156.

Hoshmand, L. T. (2004. The transformative potential of counseling education. Journal of Humanistic Counseling, Education and Development, 43(1), 82-90.

Llera, Saleem, Roffman, \& Dass-Brailsford. (2009). Teaching to Transform: Multicultural Competence and Classroom Practice. Asian Journal of Counselling, 16, 1, 51-66.

Lovat, T., \& Toomey, R. (2009). Values Education and quality teaching. The double helix effect. Callaghan: Springer Science+Business Media.

Macbeath, J. (2012). Future of teaching profession. Cambridge: University of Cambridge/Education International Research Institute.

Montero, M. L. (2000). La formación del profesorado ante los retos de la multiculturalidad. Profesorado, Revista de currículum y formación del profesorado, 4 (1), 1-20.

Oleson, A., \& Tadashi Hora, M. (2012). Teaching the Way They Were Taught? Revisiting the Sources of Teaching Knowledge and the Role of Prior Experience in Shaping Faculty Teaching Practices. Wisconsin Center for Education Research Papers, 9, 1-25.

Pérez, A. (2004). Educación para globalizar la esperanza y la solidaridad. Editorial estudios de Venezuela. Caracas: Venezuela.

Reynolds, M. (2001). Education for Inclusion, Teacher Education and the Teacher Training Agency Standards. Journal of In-Service training, 27 (3).

Singh, A. (2011). Evaluating the Impacts of Value Education: Some Case Studies International Journal of Educational Planning \& Administration, 1, 1-8.

Tarman, I., \& TarEvaluating the Impacts of Value Education: Some Case Studies man, B. (2011). Developing effective multicultural practices: a case study of exploring a teacher's understanding and practices. Uluslararası Sosyal Aratırmalar Dergisi The Journal of International Social Research, 4-17, 578-598.

Viniegra Cabello, M. (2007). Actitudes y creencias en torno a la violencia en adolescentes de Secundaria. Puls, 30, 75-101. 